Article

\title{
An Alternative Pricing System through Bayesian Estimate and Method of Moments in Bonus-Malus Framework for the Ghanaian Auto Insurance Market
}

\author{
Azaare Jacob *(1) and Zhao Wu
}

School of Management and Economics, University of Electronic Science and Technology of China, No. 2006 Xiyuan Ave, West High- Tech Zone, Chengdu 611731, China; zhaowu@uestc.edu.cn

* Correspondence: azaarejacob@yahoo.com

Received: 25 May 2020; Accepted: 30 June 2020; Published: 3 July 2020

\begin{abstract}
This paper examines the current No-Claim Discount (NCD) system used in Ghana's auto insurance market as inefficient and outmoded and therefore, proposes alternative optimal Bonus-Malus System (BMS) intended to meet the present market conditions and demand. It appears that the existing BMS fails to acknowledge the frequency and severity of policyholders' claim in its design. We minimized the auto insurance portfolios' risk through Bayesian estimation and found that the risk is well fitted by gamma, with the claim distribution modeled by the negative binomial law with the expected number of claims (a priori) as $14 \%$. The models presented in this paper recognize the longevity of accident-free driving and fully reward higher discounts to policyholders from the second year when the true characteristics of the hidden risks posed to the pool have been ascertained. The BMS finally constructed using the net premium principle is very optimal and has reasonable punishment and rewards for both good and bad drivers, which could also be useful in other developing economies.
\end{abstract}

Keywords: bonus-malus system; Ghana; Bayesian estimation; negative binomial distribution; auto insurance; Markovian process

\section{Introduction}

The role of the insurance market for economic growth and development can never be underestimated; see, for example, Stojaković and Jeremić (2016). As one of the driving forces for a country's economic growth and development, Bhoola et al. (2014) for instance states that the market needs to be well structured and established in the area of risk predictions to assure sustainability. However, Nii Anang Laryea (2016) found that unlike other countries where auto insurance business is well developed to the level that insurers use parameters such as the age of the auto and the claim history of the policyholder to predict risk, auto insurance premiums in Ghana use tariff guide from the National Insurance Commission (NIC). As a result, Awunyo-Vitor (2012) and Nii Anang Laryea (2016) revealed that the tariff guide used by the NIC in the Ghanaian auto industry is not robust and fails to consider the claims history of individual policyholder portfolios.

Risk distributions and rating factors in insurance portfolios have hidden functions which vary with time and hence are understood to be well fitted by distributions such as the negative binomial, mixed Poisson, lognormal, etc.; see Walhin and Paris (1997) and Ibiwoye et al. (2011). As a result, policyholder's career, age, gender, marital status, the type and use of automobile, location of garage, and so on are always helpful in bringing the risk into homogeneous groups and rated a priori through generalized linear models (see Renshaw 1994; Pinquet 2000; Brouhns et al. 2003; Kafkova and Krivankova 2014). However, despite all these homogenous groupings, swiftness of 
reflexes, aggressiveness behind the wheel, or information of Highway Code which have an impact on frequency and severity of claims remain other hidden factors that cannot be considered a priori; see Ibiwoye et al. (2011) and Kafková (2015). Moreover, changes in a priori information is very sensitive to the premium charged and hence must be considered with appropriate techniques; see, for instance, Gómez-Déniz et al. (2002). Therefore, because of their heterogeneous and random nature, a priori rating model on such longitudinal information needs to be dynamic, and hence the need for Bonus-Malus System (BMS).

BMS is a method introduced in auto insurance pricing by Europeans in the 1960s. With BMS, policyholders could have their annual premium discounted depending on their past claims. There are extensive studies on BMS in the actuarial literature; see, for example, Lemaire (1995), Sarabia et al. (2004), Mert and Saykan (2005), Boucher et al. (2007), and Denuit et al. (2009). Different types of methods have been used in determining fair premiums for policyholders in different classes in which the system is designed. The most popular among these methods are discrete Markov chains and Bayesian methods. Through BMS, the policyholder's annual premium is usually calculated by using only the variable random number of claims. However, it is important to construct BMS based on both the policyholder's claim frequency and severity. The reason has been that not all events produce the same amount of claims for the individual; see, for example, Gómez-Déniz (2016). Additionally, Lemaire (2004) postulated that if the severity of policyholder's claims is not included in BMS set up, the independence between the claims' number and severity is implicitly assumed. As a result, many authors, for example, Frangos and Vrontos (2001), Gómez-Déniz et al. (2014), and the recent paper from Gómez-Déniz (2016), have all discussed the risks question of implementing both variables in BMS.

In this paper, following Denuit and Dhaene (2001), Bolancé et al. (2007), Dorina et al. (2007), and Ibiwoye et al. (2011), we consider the negative binomial model, seen as a Poisson mixture distribution with gamma mixing, for claim count for auto insurance data in Ghana to obtain an optimal pricing system for the industry. With this probability law, it allows for serial dependence count of claims where gamma-distributed hidden individual non-homogenous variables are introduced. We generate the serial dependent in the count sequence of a claim by integrating the hidden or unobserved variable, then updating its forecasting ability when the individual policyholder information increases. Moreover, we incorporate both the claim frequency and severity as priors to obtain optimal BMS, which satisfies desirable transition rule. Though there are a number of distributions that could serve this purpose however, the negative binomial law is outstanding because of its convenient mathematical properties and superior fit to claim frequency data. Additionally, according to Willmot (1987), this distribution may be justified from a physical standpoint as a model to reflect heterogeneity of risk features within an automobile portfolio, or as a model to reflect the possibility of multiple claims from a single event. In that paper, the author used the Poisson-Inverse Gaussian (P-IG) distribution as a competitor to the negative binomial and argued that though the former has similar mathematical and statistical properties as the latter, its application is convenient when one has access to computers. Other evidence provided by Kestemont and Paris (1985), who generalized the P-IG, and Gossiaux and Lemaire (1981) indicate that though there are other distributions for reasonable fit, they are not without mathematical complications.

The BMS obtained using the models proposed in this work (unlike those derived under only the Poisson regression model) does modify the discounts made in the absence of claims. However, these models are little different from recent models developed by Bolancé et al. (2007) and Ibiwoye et al. (2011), which are all found in the actuarial literature. The negative binomial distribution has been considered also to deal with claim frequency and severity; see, for instance, Tremblay (1992), Schmitt (2000), Walhin and Paris (2001), Centeno and Andrade e Silva (2001), Mert and Saykan (2005), and Bülbül and Baykal (2016). Other approaches that have been considered include multidimensional credibility models by Englund et al. (1999), who assumed that each risk parameter dimension represents one cover from the business using only the policyholder's claim frequency information. Thuring (2011), for instance, also studied the effect of assuming that at least one out of two insurance policies is inactive when the latent risk profile of the policyholder is estimated. Furthermore, a multivariate credibility 
method was also used by Thuring et al. (2012), which allow insurers to look at the positive correlation in policyholders behavior between different financial policies and predict their specific risk profiles for a specific product not owned by policyholders.

Actuaries have always based on Bayesian methodology in the calculation of insurance premiums and it has proved to be a very useful tool since the mid-twentieth century as mentioned in, for example, Frangos and Vrontos (2001). In general, the Bayesian method accepts that each policyholder is denoted by a risk parameter that is unknown but random with a certain probability model in count data called a priori distribution. This method is very useful in BMS set up because it follows certain transition rules that group policyholders into either bonus or malus class. The basic Bayesian tool applied here is simply Bayes' theorem - by dividing the a posteriori mean of the parameter by the a priori mean using the net premium principle or the quadratic loss function yields an estimator for the risk parameter that classifies the policyholders into good and bad risks. For details on this and other classical examples of BMS, see, for instance, Lemaire (1995, 2004), Walhin and Paris (2001), Brannas and Hellstrom (2001), Freeland and McCabe (2004), Sarabia et al. (2004), and Denuit et al. (2009). Additionally, Mert and Saykan (2005) and Frangos and Vrontos (2001) presented empirical results that show that many vehicle insurance portfolios present a positive relationship between the above two random variables, and hence, they should be considered in the determination of BMS with the assumption that they are dependent. Furthermore, see Gourieroux and Jasiak (2004) who determined the risk for claim count using the inverse Gaussian distribution and the integer-valued autoregressive model, respectively. For more details on the pioneering research in this field, see also Lemaire (1995).

The geographical location of Ghana possibly makes the risk features in the auto insurance portfolio and the market in general different. Besides, there is a need for an optimal pricing system to sustain the industry. Therein, we examine and identify the main weakness in the existing BMS use in the Ghanaian auto insurance market, and following Denuit and Dhaene (2001), Bolancé et al. (2007), Dorina et al. (2007), and Ibiwoye et al. (2011), fit the available data with the negative binomial law. Eventually, we propose an optimal pricing system to meet the present conditions and demand to assure efficiency, growth, and sustainability of the industry.

The rest of the paper is organized as follows: Section 2 briefly describes the current practice in Ghana, while Section 3 explains the materials and methods used. Section 4 gives numerical applications to the models presented in Section 3 using the auto insurance portfolio in practice from Ghana. Finally, in Section 5, we discuss the findings, limitations of our models, implications to the insurance sector, and conclude.

\section{Contemporary Practice in Ghana}

The BMS in Ghana is acknowledged within the market as No-Claim Discount (NCD), which officially identifies three classes of cars. This is consistent with the provision of the Ghana Motor Tariff structure organized by the Insurers Association of Ghana (GIA) and the National Insurance Commission (NIC).

The first category, usually denoted as $X_{1}$ and $X_{2}$, is for private individuals and private corporate, respectively. This category allows discount based totally on a scale calculated on the basic or net renewal premium in respect of every motor vehicle. As indicated in Table 1, if policyholders presents no claim in the previous coverage year, they are given a $25 \%$ discount (bonus) during renewal. If no claim is presented during the second year, the premium discount (bonus) will shoot up to $30 \%$. For the third, fourth, and fifth claim-free coverage years, the discount would be $35 \%, 45 \%$, and $50 \%$, respectively, but cannot, however, exceed $50 \%$.

This model, as shown in Table 1, groups personal vehicle policyholders into six classes, with premium levels $100,75,70,65,55$, and 50, specified as, $i$ and $L_{5}$, respectively. Where a claim is presented in any of these periods, irrespective of the policyholder's risk class, all the discounts will be wiped out. The policyholders will then start all over again from class $L_{0}$ where they pay $100 \%$ of the yearly premium with no discount. If the policyholder moves to other insurers at the end of the year, 
they continue with the old class so long as they can show evidence of their class with the former insurer. The discount is not always cumulatively operative, and in the event of any claim, the period of discount classification starts from the following renewal year. This means that irrespective of the policyholder's class whilst claiming, he lose all the bonuses and start as a new customer in the following renewal year as already indicated.

Table 1. Personal and corporate vehicle tariffs under the current practice.

\begin{tabular}{lcccccc}
\hline \multicolumn{1}{c}{ NCD Level } & $\boldsymbol{L}_{0}$ & $\boldsymbol{L}_{1}$ & $\boldsymbol{L}_{2}$ & $\boldsymbol{L}_{3}$ & $\boldsymbol{L}_{4}$ & $\boldsymbol{L}_{5}$ \\
\hline \% Discount & 0 & 25 & 30 & 35 & 45 & 50 \\
\% Pure premium & 100 & 75 & 70 & 65 & 55 & 50 \\
\hline
\end{tabular}

Source: Ghana National Insurance Commission and Insurers Association (2015) NCD: No-Claim Discount.

The next category, in which much attention is always given to the type of car use, is commercial vehicles. Commercial vehicles have premium levels of $100,85,80$, and 75 . This implies premium discounts of $15 \%, 20 \%$, and $25 \%$ from the first to the third years, respectively.

The third category, which is solely for motorbikes, guarantees a discount of $10 \%$ regardless of the number of accident-free years. This study focuses on the first category, since it constitutes majority of active policies in the market, and its easiness in data organization. The other categories will be looked at in our subsequent study.

From the foregoing discussion, it is well understood that the authorized BMS fails to acknowledge both the frequency and severity of policyholder's claims in its design, with the assumption that they are independent, a situation clearly stated in Lemaire (2004). This results in equal punishment to all policyholders, irrespective of their number and size of reported claims in a period; see, for example, Awunyo-Vitor (2012) and Nii Anang Laryea (2016). A recent report published by GhanaWeb on the 27th December 2018 confirmed a decision by the National Insurance Commission (NIC) that there was "no more No-Claim Discount (NCD) for third-party policyholders". However, according to Lemaire (1998) and Bülbül and Baykal (2016), NCD, also known as the Bonus-Malus System, helps to increase the incentive for careful driving in developed economies. Therefore, we argue that there is a clear difficulty faced by the NIC in obtaining the best distribution that can fit the auto insurance portfolio in the market to get an advanced pricing system, and hence their decision to abolish NCD.

Second, there is an inefficient transfer of information on policyholders amongst insurance companies.

This means that, currently, the model allows a policyholder, after claiming in the course of their coverage period with one insurer, move to different competing insurer for renewal, thereby enabling them to avoid the premium surcharge. As a result, these companies lose money, erode trust and confidence, and unfortunately are unable to pay valid claims; see Varico (2002), Pitrebois et al. (2005), and Bawa (2017).

Furthermore, because of the competition in the market, most of the insurers do not follow the laid down pricing practices set up by the NIC and the GIA. Where, for instance, a discount much exceeding even $50 \%$ is occasionally arbitrarily given to new customers, thereby discrediting rating risks appropriately, increasing the hassle in the market, and adversely affecting the insurers' fortunes, as reported by Lemaire (1998), Ibiwoye et al. (2011), and Bülbül and Baykal (2016).

Based on the foregoing problems discussed, this paper, after identifying the main weakness in the existing BMS use in the Ghanaian auto insurance market, fits the available data following Denuit and Dhaene (2001), Bolancé et al. (2007), Dorina et al. (2007), and lbiwoye et al. (2011), using the negative binomial distribution. The paper finally proposes an optimal pricing system intended to meet the present market conditions and demand to ensure efficiency, growth, and sustainability of the industry. The constructed model directly solves problem one and proposes a direction for regulators to tackle problems two and three. 


\section{Methods and Materials}

The working sample contains 101,202 policyholders, which are mainly private cars merged from five major insurance companies in Ghana for a year. The data were collected through proportional sampling due to the unequal sizes of the involved companies. Before the data was analyzed, it was first cleaned to ensure that the issue of missing data and other problems were fully addressed. Therefore, frequencies of the entire dataset were computed to ascertain the actual missing values in all the variables. Results from the frequencies computed indicated 36 missing cases from the claims column out of the 101,238 cases and were therefore excluded, leaving a total of 101,202 final samples. Sorting was done to ascertain exactly the number of policyholders' claims and their corresponding observed frequencies, and the results are presented in Table 2. The parameters of the gamma distribution details of which have been provided in Section 3.3 of this paper, were estimated from the portfolio through the method of moments. See, for example, Pinquet et al. (2001) and Dorina et al. (2007) for more details. These parameters, in addition to the models presented below, aided in the BMS construction.

Table 2. Claim frequencies of policyholders in the portfolio.

\begin{tabular}{cc}
\hline Number of Claims $\boldsymbol{N}$ & Observed Frequencies \\
\hline 0 & 90,881 \\
1 & 9679 \\
2 & 516 \\
3 & 77 \\
4 & 46 \\
5 & 3 \\
$\geq 6$ & 0 \\
Total & 101,202 \\
\hline
\end{tabular}

\subsection{Information Criteria for Model Selection}

Model selection is a process used in comparing the relative values of different statistical distributions through information criterion and determines which one is best fit for the observed data. The Akaike Information Criterion (AIC), the Bayesian (or Schwarz) Information Criterion (BIC), and the Deviance Information Criterion (DIC), which is a Bayesian version or generalization of the well-known AIC, were employed to compare the models that best fit the data under consideration. Although these information criteria help in getting the best model, each attempt to adjust model fit and parsimony of factors and punishes differently for the number of parameters. Thus, to get the best model fit, these statistics were used and the one with the smaller value was preferred. For further details, see Akaike (1974), Andreas et al. (2004), and Gómez-Déniz and Calderín-Ojeda (2018).

\subsection{The Markovian Process of Policyholders in the Ghanaian NCD}

Researchers, specifically actuaries, have provided several mathematical models that are always certain that any BMS adopted by the insurance market is honest to each party in a policy. For instance, Gómez-Déniz and Calderín-Ojeda (2018) pointed that many of the BMS in existence follow a Markov chain consisting of a finite number of classes. In this case, Walhin and Paris (2001), Brouhns et al. (2003), Dionne (2005), and Gómez-Déniz and Calderín-Ojeda (2018) say premium may be reviewed upward or downward depending on policyholder's record of reported claims and follows transition rules.

The BMS in Ghana, well-known in the market as No-Claim Discount (NCD), has six classes as discount levels in percentages as

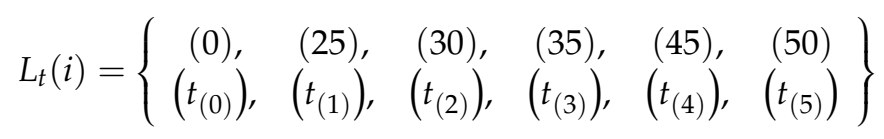


This indicates finite possible classes. If $L_{t}$, it implies that the policyholder is said to be in discount class $i$ at time $t$. We then suppose that whenever the policyholder is in discount class $i$, there exists a fixed probability vector $P_{i j}$ that he will next be in discount class $j$ at the time $t+1$.

Thus,

$$
P\left\{L_{t+1}=j / L_{t}=i, L_{t-1}=i_{t-1}, \ldots, L_{1}=i_{1}, L_{0}=i_{0}\right\}=P_{i j}, i, j, t \geq 0
$$

The probability of the policyholder at $L_{t+1}$ only depends on $L_{t}$. This phenomenon reflects the memory loss property of Markov chains. Likewise, we denote the probability that a policyholder is in discount class $L_{j}$ at the year or time $t+1$ by $P_{j}^{t+1}$. Thus, to be in discount class $L_{j}$ at time $t+1$, the policyholder has to be in a discount class $L_{i}$ at the time $t$ and then move to $L_{j}$ in the following year. Therefore, we can obtain

$$
P\left(L_{j} \text { at } t+1\right)=P_{j}^{t+1}=\sum_{i=0}^{k} P^{t} P_{j}
$$

This implies that

$$
P^{t+1}=\left(P_{0}^{t}, \ldots, P_{k}^{t}\right) \times P=P^{t} \times P
$$

In order that

$$
P^{1}=\left(P_{0}^{1}, \ldots, P_{k}^{t}\right)=\left(P_{0}^{0}, \ldots, P_{k}^{0}, \ldots, P_{k}^{0}\right) \times P
$$

Likewise, having any $t$ and $m$ one can show that

$$
P^{m+t}=\left(P_{0}^{t+m}, \ldots, P_{k}^{t+m}\right)\left(P_{0}^{t}, \ldots, P_{k}^{t}\right) \times P^{m}
$$

As indicated above, and also mentioned in lbiwoye et al. (2011), irrespective of the preliminary distribution $P^{0}$, for the bonus-malus model, there is a stationary distribution; $\pi=\left(\pi_{0}, \pi_{1}, \ldots, \pi_{k}\right)$ to which $P^{t}$ converges as $t$ turns larger. So instead of giving blanket discounts, we advise the incorporation of the severity component into the NCD to attend to specific risks associated with policyholders. Therefore, the risk premium must be set such that it depends on $T$ (where $T$ is the number of years the policyholder has been under observation) and the total size of claims reported; see Denuit and Dhaene (2001). Note that $t$ denotes a specific year, while $T$ denotes the total number of years under observation in the model by a policyholder.

Now, we consider our portfolio as a heterogeneous one, which contains information of policyholders regarding the number of claims from the last $t$ years $N(t), t=1,2, \ldots, T$, where $N(t)$ is a stochastic process representing the number of claims $N$ made by the policyholder at period $t$. This portfolio is made up of insurance policies (risk) randomly selected from several similar policies. For the portfolio being heterogeneous, we associate a random parameter $\lambda$ with cumulative density function $U(\lambda)$, which is a measure of risk for each policyholder.

\subsection{The Negative Binomial Model}

In an auto insurance policy, insurers are engaged with so many policyholders with different kinds of risk emanating from their geographical locations, age, gender, model and use of cars and so on, which have an impact on their future severity and claim frequencies. These make the risk in such a portfolio heterogeneous and independent. To deal with a portfolio of this kind and further determine the number of claims, the time between each reported claim, we propose the negative binomial law, which is seen as Poisson mixture distribution with gamma mixing. The gamma distribution has the advantage of the variance being proportional to the mean-squared when the shape parameter is held constant while the scale parameter is varied. This is very common in data such as the one under consideration. This means it is regularly appropriate for data that are continuous, positive, right-skewed, and the place variance is near-constant on the log-scale, though there are several different common picks with those properties. Moreover, the exponential distribution determines the time of reported claims in the Poisson process. The negative binomial law allows for serial dependence count 
of claims where the gamma-distributed hidden individual non-homogenous variables that represent the risk for each policyholder are introduced. We then generate the serial dependent in count sequence of claims by integrating the hidden or unobserved variable, then updating its forecasting ability when the individual policyholder information increases. Moreover, we incorporate both the claim frequency and severity as a priori to obtain optimal BMS which satisfies desirable transition rule.

To this end, given the risk parameter, $\Lambda=\lambda$, it is supposed that the conditional variables $N_{1}, N_{2} \ldots$ are independently random, which follow a Poisson distribution with parameter $\lambda>0$ (identical distributed) $P_{0}(\lambda)$ : as $N(t)$ defined above as a stochastic process that stands for the number of claims $N$ to be reported by the policyholder at $t$ period of insurance. This implies that the probability of risk $\lambda$ causing $N$ claims in $t$ years is

$$
\begin{gathered}
\prod(N, t / \lambda)=\frac{e^{-\lambda t}(\lambda t)^{N}}{N !} \\
\prod(N, t / \lambda)=\int_{0}^{\infty} \frac{e^{-\lambda t}(\lambda t)^{N}}{N} d u(\lambda), N=1,2, \ldots \infty
\end{gathered}
$$

Now, we also supposed that the risk parameter of this portfolio is represented by the gamma distribution $G(K, \beta)$ as

$$
g(\lambda)=\frac{1}{\beta^{k} \Gamma(k)} \lambda^{k-1} \exp \left(-\frac{\lambda}{\beta}\right)
$$

At this point, we also assume that $\lambda$ is exponentially distributed with $\beta$ which implies that

$$
h(\lambda)= \begin{cases}\beta e^{-\lambda \beta}, & \lambda>0 \\ 0, & \text { elsewhere }\end{cases}
$$

By employing the Bayesian theory, the distribution of the unconditional $N$ claims is generated geometrically distributed as

$$
f(N)=\beta(\beta+1)^{N+1}, N=0,1,2, \ldots
$$

Thus, having $N(t)$ as the number of claims the policyholder reports in period $t$, it implies that in $T$ years the policyholder would have a total claim as

$$
N_{T C}=\sum_{t=1}^{T} N(t)
$$

Therefore, the conditional distribution of policyholder's total claim in $T$ years is given as

$$
f\left(N_{1}, N_{2}, \ldots, N_{(t)}\right)=\frac{e^{-\lambda t} \lambda^{N_{T C}}}{\prod_{t=1}^{T} N(t) !}
$$

This means for a group of policyholders with $N_{1}, N_{2}, \ldots, N_{(t)}$ claims history, the posterior function structure is obtained as

$$
f\left(\lambda / N_{1}, N_{2}, \ldots, N_{(t)}\right)=\frac{(t+\beta)^{N_{T C}+1}}{\Gamma\left(N_{(T C)}+1\right)} e^{-\lambda(t+\beta) \lambda^{N_{T C}}}, \lambda>0
$$

As a result, the estimate for the expected number of claims of a policyholder with reported claims $N_{1}, N_{2}, \ldots, N_{(t)}$ can be found with the help of the quadratic loss function as

$$
\hat{\lambda}_{t+1}=\frac{N_{T C}+1}{\beta+1}
$$


As indicated above, the number of policyholder's claim $N$ is Poisson distributed with risk parameter $\lambda$. Following Denuit and Dhaene (2001), Bolancé et al. (2007), Dorina et al. (2007), and Ibiwoye et al. (2011), and considering the fact that $\lambda$ also follows a gamma distribution with parameters $G(K, \beta)$, it implies that the discrete random variable $N_{T C}$ (total claims) and the probability density function of the negative binomial distribution with $r \geq 0,0 \leq P \leq 1 P$ can be deduced as

$$
P\left(N_{T C}=k\right)=\frac{\Gamma(r+k)}{k ! \Gamma(r)} P^{r}(1-P)^{k}, k=1,2, \ldots
$$

Therefore, the unconditional distribution of claim number with the gamma parameters $K$ and $\beta$ is found as

$$
f(N)=\left(\begin{array}{c}
N+K-1 \\
N
\end{array}\right)=\left(\frac{\beta}{1+\beta}\right)^{k}\left(\frac{\beta}{1+\beta}\right)^{N}, N=1,2, \ldots
$$

Hence, we obtained the expected value of the claim number with regards to the gamma distribution as

$$
\left(\lambda / N_{1}=n_{1}, N_{2}=n_{2}, \ldots, N_{(t)}=n_{t}\right)=\frac{K+N_{T C}}{t+\frac{1}{\beta}}
$$

Considering the conditional distribution of the claims at $t+1$, (17) can be obtained. This shows that the expected number of claims at $t+1$ depends on only the number of total claims $N_{T C}$ in the previous year. Moreover, the fact that the number of claims follows a negative binomial distribution means the first-year insurance would yield the parameter $N B\left(r=k, p=\frac{1}{1+\beta}\right)$ and this leads us to the expected claims number as

$$
E\left(N_{1}\right)=K\left(1-\frac{1}{\beta+1}\right)(\beta+1)=K \beta
$$

Finally, the expected number of claims for a policyholder with $N_{1}, N_{2}, \ldots, N_{T}$ claim history is estimated as

$$
\hat{\lambda}_{t+1}=\frac{K+N_{T C}}{\left(t+\frac{1}{\beta}\right) K \beta}
$$

\subsection{Severity Distribution of Claim}

Concerning claim severity, several mathematical models ensure that any adopted BMS is optimal and also honest to parties in an insurance policy; see Mert and Saykan (2005) and Ibiwoye et al. (2011). As there is no difference between policyholders having an accident with a small or big size of the loss, these systems can be said to be unfair. Therefore, as reported by Centeno and Andrade e Silva (2001), an optimal system that takes both the frequency and severity component into account must be used to set up the premium a policyholder should pay. An optimal BMS should also be efficient and at the same time competitive and this is attained when it is financially balanced for the insurer and fair to the policyholder; see Frangos and Vrontos (2001) and Dorina et al. (2007).

At this moment, we consider the severity or the size of policyholders' reported claims for our portfolio by relying on the inverse gamma distribution. We therefore let $C_{t}$ be the size of claims made by each policyholder having not equal mean size $\lambda$ inverse gamma with $K$ and $\beta$ defined by

$$
f(\lambda)= \begin{cases}\frac{1 / \beta e^{-\beta / \lambda}}{(\lambda / \beta)^{K+1} \Gamma(K)}, & K, \beta, \lambda>0 \\ 0, & \text { elsewhere }\end{cases}
$$


We obtained TC as the total claim size which is equal to $\sum_{t=1}^{T} C_{t}$. By using the Bayesian estimation, the distribution of claim size $C_{t}$ unconditionally is found as Pareto with $K$ and $\beta$ parameters. The estimate of the expected claim amount for a policyholder with claim size history $C_{1}, C_{2}, \ldots, C_{T}$ is hence equal to

$$
\hat{\lambda}_{t+1}=\frac{\beta+T C}{K+N_{T C}-1}
$$

\subsection{Determination of Basic Premium}

At the beginning of every insurance policy $(t=0)$, which implies that the policyholder has no discount and the premium charged is $100 \%$. Thus, the risk premium for a policyholder combining his frequency and severity into effect at $t+1$ would be equal.

3.5.1. Considering the Claim Frequency only

Poisson-exponential mixture:

$$
t+1=100 \times \frac{N_{T C}+1}{\beta+t}
$$

Poisson-gamma mixture:

$$
t+1=100 \times \frac{K+N_{T C}}{\left(t+\frac{1}{\beta}\right) K \beta}
$$

\subsubsection{Considering Claim Frequency and Severity}

Poisson-exponential mixture with exponential inverse gamma:

$$
t+1=100 \times\left(\frac{N_{T C+1}}{\beta+t}\right)\left(\frac{\beta+T C}{K+N_{T C}-1}\right)
$$

Poisson-gamma mixture with exponential inverse gamma:

$$
t+1=100 \times\left(\frac{N_{T C}+K}{\left(t+\frac{1}{\beta}\right) K \beta}\right)\left(\frac{\beta+T C}{K+N_{T C}-1}\right)
$$

It should be noted that an insurance firm can include the depreciation of the car into any of the premium determination cases if the rate of the depreciation is known.

\section{Numerical Applications}

At this point, to determine the pricing system based on the models introduced, we examine a set of data that involves information based on one year auto insurance policies. This dataset was taken from major Ghanaian insurance companies from January to December 2017 which contains 101,202 policies of which 10,321 have at least one claim.

The minimum and the maximum concerning the number or frequency of claims are 0 and 5 , respectively, as shown in Table 3. The mean, the variance, and the standard deviation were respectfully estimated to be $0.1101,0.1188$, and 0.3447 . After obtaining these values (mean $<$ variance) and the goodness-of-fit criteria information in Table 4 , we were convinced that the negative binomial distribution suits our data well; see Denuit and Dhaene (2001), Bolancé et al. (2007), Dorina et al. (2007), and Gómez-Déniz and Calderín-Ojeda (2018) for details. We then proceeded to provide the model fit using (6) and (15) in Table 2. Moving forward, regarding the claim size, we obtained the minimum and the maximum, respectively, as 0 and 77,724.0. The mean is 1851.14 and the standard deviation is $275,776.26$. It is observed here that the latter statistic is very large as the mean size of claims, and therefore, if we based on their division using the Bayesian method for our pricing system, it would 
not be adequate. We therefore consider the method of moments for our model parameters estimated as $\hat{p}=0.9268, \hat{r}=1.40$, where $\hat{K}=\hat{r}=1.40$ and $\beta=0.10$. These estimators were obtained using the above sample mean and variance from our portfolio; see Pinquet et al. (2001) and Dorina et al. (2007) for more details. The implication is, therefore, that the risk parameter average for this portfolio is $K . \beta=0.14$. Thus, the expected number of claims (a priori) is $14 \%$.

Table 3. Fitting the claims number with Poisson and negative binomial distribution.

\begin{tabular}{llll}
\hline \multicolumn{1}{c}{$\boldsymbol{N}$} & Observed & Poisson & Negative Binomial \\
\hline 0 & 90,881 & 90,651 & 91,027 \\
1 & 9679 & 9981 & 9288 \\
2 & 516 & 549 & 814 \\
3 & 77 & 20 & 67 \\
4 & 46 & 1 & 5 \\
5 & 3 & 0 & 1 \\
$\geq 6$ & 0 & 0 & 0 \\
Total & 101,202 & 101,202 & 101,202 \\
\hline
\end{tabular}

Table 4. The goodness-of-fit criteria for the claim number and size in the auto insurance portfolio in Ghana.

\begin{tabular}{ccccc}
\hline Distribution & CAIC & BIC & DIC & $\chi^{2}$ \\
\hline Poisson & $243,903,789.70$ & $243,903,784.70$ & $245,273,880.80$ & 3320.814 \\
Negative Binomial & $1,762,717.96$ & $1,762,712.96$ & $114,518.32$ & 1.490 \\
\hline
\end{tabular}

The Proposed Pricing Systems

Here, we consider the estimated parameters from our data and use our models specifically (22) and (23) to propose simple a posteriori pricing system that depend on the net premium principle shown in Tables 5 and 6, respectively. From Tables 5 and 6, it is observed that these structures are built similarly just like those in a traditional BMS. Thus, at the start of the model $(t=0)$, the base premium is taken as 100 percent. Then these premiums decrease after a year of no claims, then increase when claims are reported. The risk premiums are calculated for years and the various numbers of claim $N=0,1, \ldots, 10$, and the results obtained are given in Tables 5 and 6 as mentioned. For comparison purposes, readers can refer to Walhin and Paris (1997), Guerreiro and Mexia (2002), Mert and Saykan (2005), Dorina et al. (2007), and Ibiwoye et al. (2011) for details on BMS constructed using the net premium principle. As viewed from the tables, these BMS can be seen as being fair to good drivers and strict with bad drivers.

Table 5. Optimal Bonus-Malus System (BMS) based on the posteriori frequency component (Poisson-exponential).

\begin{tabular}{cccccccccccc}
\hline $\mathbf{t} / \mathbf{N}$ & $\mathbf{0}$ & $\mathbf{1}$ & $\mathbf{2}$ & $\mathbf{3}$ & $\mathbf{4}$ & $\mathbf{5}$ & $\mathbf{6}$ & $\mathbf{7}$ & $\mathbf{8}$ & $\mathbf{9}$ & $\mathbf{1 0}$ \\
\hline 0 & 100 & - & - & - & - & - & - & - & - & - & - \\
1 & 91 & 182 & 273 & 364 & 455 & 545 & 636 & 727 & 818 & 909 & 1000 \\
2 & 48 & 95 & 143 & 190 & 238 & 286 & 333 & 381 & 429 & 476 & 524 \\
3 & 32 & 65 & 97 & 129 & 161 & 194 & 226 & 258 & 290 & 323 & 355 \\
4 & 24 & 49 & 73 & 98 & 122 & 146 & 171 & 195 & 220 & 244 & 268 \\
5 & 20 & 39 & 59 & 78 & 98 & 118 & 137 & 148 & 176 & 196 & 216 \\
6 & 16 & 33 & 49 & 66 & 82 & 98 & 115 & 131 & 148 & 164 & 180 \\
7 & 14 & 28 & 42 & 56 & 70 & 86 & 99 & 113 & 127 & 141 & 155 \\
8 & 12 & 25 & 37 & 49 & 62 & 74 & 86 & 99 & 111 & 123 & 136 \\
9 & 11 & 22 & 33 & 44 & 55 & 66 & 77 & 88 & 99 & 110 & 121 \\
10 & 10 & 20 & 30 & 40 & 50 & 59 & 69 & 79 & 89 & 99 & 109 \\
\hline
\end{tabular}


Table 6. Optimal BMS based on the posteriori frequency component (Poisson-gamma mixture).

\begin{tabular}{cccccccccccc}
\hline $\mathbf{t} / \mathbf{N}$ & $\mathbf{0}$ & $\mathbf{1}$ & $\mathbf{2}$ & $\mathbf{3}$ & $\mathbf{4}$ & $\mathbf{5}$ & $\mathbf{6}$ & $\mathbf{7}$ & $\mathbf{8}$ & $\mathbf{9}$ & $\mathbf{1 0}$ \\
\hline 0 & 100 & - & - & - & - & - & - & - & - & - & - \\
1 & 91 & 156 & 221 & 279 & 351 & 416 & 481 & 545 & 610 & 675 & 740 \\
2 & 83 & 143 & 202 & 162 & 321 & 381 & 440 & 500 & 560 & 619 & 679 \\
3 & 77 & 132 & 187 & 242 & 297 & 352 & 407 & 462 & 516 & 571 & 626 \\
4 & 71 & 122 & 173 & 224 & 276 & 327 & 376 & 429 & 480 & 531 & 582 \\
5 & 67 & 114 & 162 & 210 & 257 & 305 & 352 & 400 & 448 & 495 & 543 \\
6 & 63 & 107 & 152 & 196 & 241 & 288 & 330 & 375 & 420 & 462 & 510 \\
7 & 59 & 101 & 143 & 185 & 227 & 269 & 311 & 353 & 395 & 437 & 479 \\
8 & 56 & 95 & 135 & 175 & 214 & 254 & 294 & 333 & 373 & 413 & 452 \\
9 & 53 & 90 & 128 & 165 & 203 & 240 & 285 & 316 & 353 & 391 & 429 \\
10 & 50 & 86 & 121 & 157 & 193 & 229 & 264 & 300 & 336 & 371 & 407 \\
\hline
\end{tabular}

Furthermore, to include the effect of each claim frequency and severity component before setting the premium for the policyholder, a BMS based on this aspect is also considered. With the estimated parameters, $K=1.40$ and $\beta=0.10$, it can be based on (24) and (25) to obtain an optimal pricing system which takes into account both claim frequency and severity when the aggregate claim sizes of respective policyholders are known. In this case, the bigger the policyholder's claim size, the higher their risk premium.

\section{Discussions}

Unlike the present practice, where a discount of 25 percent is given in the first year to a policyholder who has no claim, our system as shown in Tables 5 and 6 rewards a policyholder without an accident after the first policy year with a premium discount of 9 percent, a situation which is little different from previous contributions by Walhin and Paris (1997), Dorina et al. (2007), and Ibiwoye et al. (2011). The 9 percent discount for claim-free driver after the first year may sound very unfair but we suppose it is important to the insurers since a period of one year may not be enough to ascertain the real characteristics of the hidden risk imposed to the pool by the driver. Given this, a discount of 52 percent from Table 5 and 17 percent from Table 6 are given to these good drivers in the second accident-free year. Although this 52 percent especially may additionally elevate subject about profitability however, it is an acknowledged fact that competition amongst the industry players already makes this the actual practice in Ghana. On the contrary, if one claim is recorded after one year, the policyholder is penalized with a premium increment of 82 percent and 56 percent according to our model in Tables 5 and 6, respectively - a situation that seems very hard on drivers who may report claims within their first year of the policy. Moreover, if two claims are made within the first year, the penalty increases to 173 percent in Table 5 and 121 percent in Table 6 and so on.

The existing model in the market compared with our proposed ones does not recognize the number of previous claims but in reality only returns the insured to the initial state; see Awunyo-Vitor (2012) and Nii Anang Laryea (2016). The additional uniqueness of our model is that it recognizes the long existence of safe driving. Whereas in the current system, there is no additional incentive after a period of five years other than the 50 percent discount as indicated in Table 1 on premium for a careful driver who reports no accident, our model extends the incentive to ten years. A policyholder who reports no accident in ten years can expect to get a discount as high as ninety percent $(90 \%)$ of the initial premium according to our model in Table 5. Moreover, comparing the model in Table 6 with the existing model in Table 1 shows an interesting result. Thus, whereas the existing system in Table 1 takes five years for claims-free driver to enjoy 50 percent premium discount, our model in Table 6 will take them ten years. Furthermore, if within the first year of the contract the policyholder makes as many as five claims, then the penalty for the next policy year can rise as high as over 400 percent and 300 percent of the initial premium, respectively, from Tables 5 and 6. Thus, instead of moving up and down on what has been termed "flat rates" of premium under the current system, our model 
encourages premium assessment based on the claims history of the policyholder, just as indicated in Lemaire (1995), Bolancé et al. (2007), Dorina et al. (2007), and Ibiwoye et al. (2011). Finally, it worth mentioning that though our models in both Tables 5 and 6, given the current pricing shortfalls in the market, would be very useful; however, the model in Table 6 would be less competitive and more profitable in its application.

Despite the contributions of this study to the auto insurance pricing system in Ghana, it is important to reflect upon its limitations. One is the way we organized our data from different companies because we needed a reasonable sample size to deal with. This limited us from accessing individual policyholder's risk based on their other rating factors like age, vehicle type, and so on, which we suggest future researchers to look into. Moreover, while it is statistically agreed that the negative binomial distribution is good for fitting heterogeneous portfolios like ours, we however, admit that there are other distributions that could have also been considered for our proposed model. Furthermore, the distribution and the estimated parameters make the paper technical. Therefore, it worth mentioning that, though this paper looks technical, our model fits very well with the portfolio considered, and hence, based on the market and the problems to be addressed, this paper would be applicable. Again, it would also be interesting to know the challenges faced in our data acquisition process. Thus, due to the existing market competition and a well-known fact on the difficulty in acquiring financial data, management from the various companies were reluctant to give us information. However, with continuous engagements, this issue was finally addressed.

\subsection{Implications for the Insurance Industry}

The practical implications of our study are straightforward. To boost the effective auto insurance pricing system in Ghana, the industry players could rely on the negative binomial law to model policyholder's claims or implement the findings in this paper. The NIC and the GIA should focus on fair pricing systems that incorporate both the frequency and severity components to ensure that policyholders pay premiums proportional to their respective risk. There is unavailable information on policyholders, which all the companies can have access to. This has led to much undercutting in premiums under the present pricing system. Therefore, implementation of our findings would translate to the fact that irrespective of policyholder's mother company, there will be a unified pricing system that would be applicable to all depending on their associated risk. Implementation of this kind of pricing system would also have a positive impact on claim reduction. BMS can increase the incentive for careful driving, and for that matter, policyholders would drive in a manner to reduce possible road accidents. Though this could go a long way to increase the bonus hunger effect in the industry, however, it will benefit the industry players to be financially solvent. This paper also revealed that the risk a priori is $14 \%$. This means that the industry would have an advantage in their planning towards all future claims having this a priori information.

\subsection{Conclusions}

The proper risk prediction model in every insurance sector is prerequisite information to achieve optimal pricing for sustainable growth and development. Despite the numerous contributions of BMS as a pricing tool for insurance markets in developing and developed economies, auto insurance premiums in Ghana are determined using the tariff guide from the National Insurance Commission (NIC) as stated by Nii Anang Laryea (2016). As a result, Awunyo-Vitor (2012) and Nii Anang Laryea (2016) find that the current pricing system in the Ghanaian auto industry is not robust because it fails to consider the claims history of individual policyholders, making it very unfair and not optimal. To address the above phenomenon, we investigated in this paper the best distribution for the Ghanaian auto insurance data and finds it is well modeled by negative binomial distribution. We therefore, consider this distribution seen as Poisson mixture distribution with gamma mixing for the claims count, and through the method of moments and the Bayesian theorem, estimate the portfolio parameters. It is 
revealed from our portfolio that the mean of the risk parameter is 0.14 , which implies an average frequency (a priori) claim as $14 \%$.

Finally, based on the simple models introduced, we employed the net premium principle to obtain an optimal BMS which takes into account the policyholder's claims history. These structures are built similarly, just like those in traditional BMS. Thus, at the start of the model $(t=0)$, the base premium is taken as 100 percent. Then these premiums decrease after a year of no claims, then increase when claims are reported. The BMS obtained using the models proposed in this work (unlike those derived under only the Poisson regression model) does modify the discounts made in the absence of claims. This system looks a little technical, however, implementing it would be fair to both the insurer and the policyholder and would assure sustainability and growth of the industry in the long run when serving as an incentive towards careful driving.

Author Contributions: Conceptualization, A.J. and Z.W.; methodology, A.J. and Z.W.; software, A.J.; validation, A.J. and Z.W.; formal analysis, A.J.; investigation, A.J. and Z.W.; resources, Z.W.; writing-original draft preparation, A.J.; writing-review and editing, A.J.; supervision, Z.W.; funding acquisition, Z.W. All authors have read and agreed to the published version of the manuscript.

Funding: This work was supported by the National Science foundation of China (project No: 71871044).

Conflicts of Interest: The authors declare no conflict of interest.

\section{References}

Akaike, Hirotugu. 1974. A new look at the statistical model identification. IEEE Transaction on Automatic Control 19: 716-23. [CrossRef]

Andreas, Berg, Renate Meyer, and J. Yu. 2004. Deviance Information Criterion for Comparing Stochastic Volatility Models. American Statistical Association Journal of Business and Economic Statistics 22: 1-14.

Awunyo-Vitor, Dadson. 2012. Comprehensive Motor Insurance Demand in Ghana: Evidence from Kumasi Metropolis. Management 4: 80-86. [CrossRef]

Bawa, L.L. 2017. Oxford Business Group Interview Published in the Report. Ghana: Ghana National Insurance Commission (NIC).

Bhoola, Kerisha, Takalani Madzhadzhi, J. Narayan, S. Strydom, and H. H. Van Heerden. 2014. Insurance Regulation in Africa: Impact on Insurance and Growth Strategies. Paper presented at the Actuarial Society of South Africa's 2014 Convention, Cape Town, South Africa, October 22-23; pp. 1-53.

Bolancé, Catalina, Denuit Michel, Montserrat Guillen, and Philippe Lambert. 2007. Greatest Accuracy Credibility with Dynamic Heterogeneity: The Harvey-Fernandes Model. Belgian Actuarial Bulletin 7: 14-18.

Boucher, Jean-Philippe, Montserrat Guillen, Michel Denuit, and P. Morrison. 2007. Risk classification for claim counts: A comparative analysis of various zero-inflated mixed Poisson and hurdle models. North American Actuarial Journal 11: 110-31. [CrossRef]

Brannas, Kurt, and Jorgen Hellstrom. 2001. Generalization to the AR(1) Count Data Model. Econometric 20: $425-43$. Brouhns, N., M. Denuit, M. Guillen, and J. Pinquet. 2003. Bonus-Malus Scales in Segmented Tariffs with Stochastic Migration between Segments. Journal of Risk and Insurance 70: 577-99. [CrossRef]

Bülbül, Serpil Ergun, and Kemal Burak Baykal. 2016. Optimal Bonus-Malus System Design in Motor Third-Party Liability Insurance in Turkey: Negative Binomial Model. International Journal of Economics and Finance 8: 205-11. [CrossRef]

Centeno, Maria de Lourdes, and Joao Manuel Andrade e Silva. 2001. Bonus systems in an Open Portfolio. Insurance Mathematics and Economics 28: 341-50. [CrossRef]

Denuit, Michel, and Jan Dhaene. 2001. Bonus-Malus Scales Using Exponential Loss Functions. Springer Link 25: 13-27. [CrossRef]

Denuit, Michel, Marechal Xavier, Sandra Pitrebois, and Jean-Francois Walhin. 2009. Actuarial Modelling of Claim Counts Risk Classification, Credibility and Bonus-Malus Systems. Hoboken: John Wiley \& Sons.

Dionne, G. 2005. The 1992 Bonus-Malus System in Tunisia: An Empirical Evaluation. Journal of Risk and Insurance 72: 609-33. [CrossRef]

Dorina, Laz, Laz Ioan, and Ilie Parpucea. 2007. Theoretical and Practical Considerations Regarding Bonus-Malus System. Acta University Apulensis 13: 57-66. 
Englund, Martin, Jim Gustafsson, Jens Nielsen Perch, and Fredrik Thuring. 1999. Multidimensional credibility with time effects: An application to commercial business lines. The Journal of Risk and Insurance 76: 443-53. [CrossRef]

Frangos, Nicholas, and Spyridon Vrontos. 2001. Design of optimal Bonus- Malus Systems with a Frequency and a Severity Component on an individual Basis in Automobile Insurance. ASTIN Bulletin 31: 1-22. [CrossRef]

Freeland, R. Keith, and Brendan P. M. McCabe. 2004. Forecasting Discrete Valued Low Count Time Series. International Journal of Forecating 20: 427-34. [CrossRef]

Ghana National Insurance Commission and Insurers Association. 2015. Minimum Motor Insurance Tariff Underwriting and Implementation Guidelines. Accra: Ghana National Insurance Commission and Insurers Association.

Gómez-Déniz, Emilio. 2016. Bivariate Credibility Bonus-Malus Premiums Distinguishing Between two Types of Claims. Insurance: Mathematics and Economics 70: 117-24. [CrossRef]

Gómez-Déniz, Emilio, and Enrique Calderín-Ojeda. 2018. Multivariate Credibility in Bonus-Malus systems Distinquishing between Different Types of Claimsin. Journal of Risks 34: 1-11.

Gómez-Déniz, Emilio, Francisco-Jose Vázquez-Polo, and J. M. Perez-Sánchez. 2002. Measuring Sensitivity in a Bonus-malus system. Insurance: Mathematics and Economics 31: 105-13.

Gómez-Déniz, Emilio, Agustin Hernández-Bastida, and M. Pilar Fernández-Sánchez. 2014. Computing credibility bonus malus premiums using the total claims amount distribution. Hacettepe Journal of Mathematics and Statistics 43: 47-61.

Gossiaux, A., and J. Lemaire. 1981. Methodes d'ajustement de distributions de sinistres. Bulletin of the Association of Swiss Actuaries 81: 87-95.

Gourieroux, Christian, and Joann Jasiak. 2004. Heterogeneous INAR (1) Model with Application to Car Insurance. Insurance. Mathematics and Economics 34: 177-92. [CrossRef]

Guerreiro, Gracinda Rita, and Joao T. Mexia. 2002. An alternative Approach to Bonus Malus. Discussiones Mathematicae Probability and Statistics 24: 197-213.

Ibiwoye, Ade, I. A. Adeleke, and Sunday A. Aduloju. 2011. Quest for Optimal Bonus-Malus in Automobile Insurance in Developing Economies: An Actuarial Perspective. International Business Research 4: 74-83. [CrossRef]

Kafková, Silvie. 2015. Bonus-Malus Systems in Vehicle Insurance. Procedia Economicand Finance 23: $216-22$. [CrossRef]

Kafkova, Silvie, and Lenka Krivankova. 2014. Generalized Linear Models in Vehicle Insurance. Acta University Agriculturae et Silviculturae Mendelianae Brune 60: 383-88. [CrossRef]

Kestemont, R., and J. Paris. 1985. Sur l'ajustement du nombre de sinistres. Bulletin of the Association of Swiss Actuaries 85: $157-64$.

Lemaire, Jean. 1995. Bonus-Malus Systems in Automobile Insurance. 19 vols. New York: Kluwer Academic Publishers, pp. 3-10.

Lemaire, Jean. 1998. Bonus-Malus Systems: The European and Asian approach to merit-rating. North American Actuarial Journal 2: 26-38. [CrossRef]

Lemaire, Jean. 2004. Bonus-Malus Systems. In Encyclopedia of Actuarial Science. Hoboken: Wiley John Wiley \& Sons.

Mert, Mehmet, and Y. Saykan. 2005. On a Bonus-Malus System where the Claim Frequency Distribution is Geometric and the Claim Severity is Perato. Hacettepe Journal of Mathematics and Statistics 34: 75-81.

Nii Anang Laryea, Philip. 2016. Estimating the Risk Premium of Motor Insurance in Ghana using the Empirical Bayesian Credibility Theory Model. Master's dissertation, Kwame Nkrumah University of Science and Technology, Kumasi, Ghana; pp. 1-81.

Pinquet, Jean. 2000. Experience Rating Through Heterogeneous Models. In Handbook of Insurance. Edited by G. Dionne. 22 vols. Amsterdam: Amsterdam Kluwer Academic Publisher, pp. 459-500.

Pinquet, Jean, Montserrat Guillen, and Catalina Bolancé Losilla. 2001. Long-range contagion in automobile insurance data: estimation and implications for experience rating. ASTIN Bulletin 31: 337-48. [CrossRef]

Pitrebois, Sandra, Michel Denuit, and Jean-Francois Walhin. 2005. Bonus-malus systems with varying deductibles. ASTIN Bulletin 35: 216-74. [CrossRef]

Renshaw, Arthur E. 1994. Modelling the Claims process in the presencce of Covariate. ASTIN Bulletin 24: 265-85. [CrossRef] 
Sarabia, Jose Maria, Emilio Gómez-Déniz, and F. J. Vázquez-Polo. 2004. On the use of conditional specification models in claim count distributions: An application to bonus-malus systems. ASTIN Bulletin 34: 85-89. [CrossRef]

Schmitt, Karen E. 2000. European Auto Insurance Pricing Considerations: Casualty Actuarial Society Forum. Winter. pp. 141-58. Available online: https://www.casact.org (accessed on 25 May 2020).

Stojaković, Aleksandra, and Ljilana Jeremić. 2016. Development of the Insurance Sector and Economic Growth in Countries in Transition. Scientific Review Article 13: 83-106. [CrossRef]

Thuring, Fredrik. 2011. A credibility method for profitable cross-selling of insurance products. Annals of Actuarial Science 6: 65-75. [CrossRef]

Thuring, Fredrik, Jens Nielsen Perch, Montserrat Guillén, and Catalina Bolancé Losilla. 2012. Selecting propects for cross-sellings financial products using multivariate credibility. Expert Systems with Applications 39: 9-16. [CrossRef]

Tremblay, Luc. 1992. Using the Poisson inverse Gaussian Distribution on Bonus-Malus System. ASTIN Bulletin 22: 97-106. [CrossRef]

Varico, Paola. 2002. Bonus-malus systems: Lack of Transparency and Adequate Measure. ASTIN Bulletin 32: 315-18. [CrossRef]

Walhin, Jean-Francois, and John Paris. 1997. Using Mixed Poisson Processes in Connection with Bonus-Malus Systems. ASTIN Bulletin 29: 81-99. [CrossRef]

Walhin, Jean-Francois, and John Paris. 2001. The Practical Replacement of a Bonus-Malus System. Catholic University of Louvain in Belgian 1: 317-35. [CrossRef]

Willmot, Gordon E. 1987. The Poisson-Inverse Gaussian distribution as an alternative to the negative binomial. Scandinavian Actuarial Journal 1987: 113-27. [CrossRef]

(C) 2020 by the authors. Licensee MDPI, Basel, Switzerland. This article is an open access article distributed under the terms and conditions of the Creative Commons Attribution (CC BY) license (http://creativecommons.org/licenses/by/4.0/). 